\title{
Nutritional Rickets and Osteomalacia in the Twenty-first Century: Revised Concepts, Public Health, and Prevention Strategies
}

\author{
Suma Uday ${ }^{1}$ • Wolfgang Högler ${ }^{1,2}$ \\ Published online: 13 June 2017 \\ (C) The Author(s) 2017. This article is an open access publication
}

\begin{abstract}
Purpose of Review Nutritional rickets and osteomalacia are common in dark-skinned and migrant populations. Their global incidence is rising due to changing population demographics, failing prevention policies and missing implementation strategies. The calcium deprivation spectrum has hypocalcaemic (seizures, tetany and dilated cardiomyopathy) and late hypophosphataemic (rickets, osteomalacia and muscle weakness) complications. This article reviews sustainable prevention strategies and identifies areas for future research. Recent Findings The global rickets consensus recognises the equal contribution of vitamin D and dietary calcium in the causation of calcium deprivation and provides a three stage categorisation for sufficiency, insufficiency and deficiency. For rickets prevention, $400 \mathrm{IU}$ daily is recommended for all infants from birth and $600 \mathrm{IU}$ in pregnancy, alongside monitoring in antenatal and child health surveillance programmes. Summary High-risk populations require lifelong supplementation and food fortification with vitamin D or calcium. Future research should identify the true prevalence of rickets and osteomalacia, their role in bone fragility and infant mortality, and best screening and public health prevention tools.
\end{abstract}

Keywords Nutritional rickets · Osteomalacia · Vitamin D . Supplementation policy $\cdot$ Food fortification $\cdot$ Dietary calcium

This article is part of the Topical Collection on Paediatrics

Wolfgang Högler

wolfgang.hogler@bch.nhs.uk

1 Department of Endocrinology and Diabetes, Birmingham Children's Hospital, Steelhouse Lane, Birmingham B4 6NH, UK

2 Institute of Metabolism and Systems Research, University of Birmingham, Birmingham, UK

\section{Introduction}

The incidence of nutritional rickets (NR) is rising globally [1], and hospitalisation is increasing even in high income countries $[2 \bullet \bullet, 3]$. The underlying calcium deprivation $[4 \bullet]$ does not just manifest as reduced bone mineralisation (rickets and osteomalacia) but also as hypocalcaemic seizures, tetany and dilated cardiomyopathy including cardiac failure and death $[5,6,7 \cdot]$. Undiagnosed NR has also been implicated in childhood mortality $[8 \cdot, 9]$. The prevalence of osteomalacia histologically at post-mortem in adult Europeans is as high as $25 \%$ [10•]. Therefore, clinically evident NR is only the tip of the iceberg, and the true burden of subclinical rickets and osteomalacia remains unidentified. Calcium deprivation is caused by two factors, low dietary calcium and vitamin $\mathrm{D}$ intake. Vitamin D deficiency is pandemic in Europe [11•], in winter affecting nearly $18 \%$ of the population, but with 3-71 times higher risk in dark-skinned ethnic minority groups [11•]. The increasing prevalence of vitamin D deficiency mirrors the trends in NR, dark-skinned individuals being at a higher risk $[12 \bullet \cdot]$.

\section{Rickets and Osteomalacia-Definition, Risk Groups and Terminology}

\section{Definition}

Rickets constitutes the defective mineralisation of growth plates $[13 \bullet \bullet, 14,15]$. The underlying mechanism of all forms of rickets is low serum phosphate resulting in reduced apoptosis of hypertrophic chondrocytes in the growth plate and reduced mineralisation of primary spongiosa in the metaphysis (new bone) [16]. In NR, hypophosphataemia is created by secondary hyperparathyroidism (see below). 
Osteomalacia constitutes defective mineralisation of existing (old) bone during the remodelling process and therefore always goes along with rickets in growing children (open growth plates) and occurs ubiquitously in bones of adults or adolescents (closed growth plates). Therefore, osteomalacia is not just a disease of adults, but the main reason for long bone bowing deformities and fractures in children with rickets, as poor mineralisation reduces bone stiffness. Low calcium intake and/or low vitamin D (from lack of sunshine exposure) are the leading causes of body calcium deprivation worldwide and their combined deficiency accelerates bone demineralisation $[13 \bullet \cdot, 14,17]$.

\section{Risk Groups}

Public health research has identified traditional diets low in calcium, dark skin and cultural full body clothing, as the predominant causes of rickets and osteomalacia in sunny parts of the world such as the Indian subcontinent $[18 \bullet, 19]$, the Middle East [20] and Africa [21]. In high Northern or Southern latitudes (more than approximately $34^{\circ}$ ), it is the seasonal lack of the ultraviolet-B (UV-B) spectrum of sunlight that causes seasonal vitamin D deficiency (also called 'vitamin D winter') [11•]. In high latitude countries, the darkskinned immigrant and resident population is at greatest risk $[12 \bullet \bullet$.

\section{Terminology De-confused}

Vitamin D (calciferol) is made in the human skin (D3) following exposure to UV-B light, or ingested with food (D2 and D3), then converted in the liver to 25-hydroxyvitamin D (25OHD, calcidiol) and finally in the kidney and also the gut [22] to the active hormone $1,25(\mathrm{OH})_{2} \mathrm{D}$ (calcitriol or 'active vitamin D'). Sadly, this terminology has confused generations of healthcare professionals. Even today, conference presenters refer to calciferol, calcidiol and calcitriol as 'vitamin D'. To add to the confusion, all three steroids exist either in their D2 (ergo-) or D3 (chole-) form, not to mention other, poorly explored secosteroid versions of this vitamin. Vitamin D and 25OHD are biologically inert, whereas calcitriol is the active, potent hormone with its main function to increase intestinal absorption of calcium and phosphate. Experts in adrenal and sex-steroids are well used to dealing with steroid terminology, various hydroxylation steps, and the concept of inert and active metabolites. In analogy to other steroid pathways, cortisol is not 'active cholesterol', or the mineralocorticoid receptor is not a 'cholesterol receptor'. Vitamin D does not bind to the 'vitamin D receptor', only calcitriol does and hence the appropriate term for this receptor is 'calcitriol receptor'. This is not a semantic discussion. Even in the twenty-first century, there are reports where calcitriol is used incorrectly to replace severe vitamin $\mathrm{D}$ deficiency, which not only leaves the individual vitamin D deficient but worsens the situation by suppressing 25-hydroxylase activity and risking hypercalcaemia. The correct replacement for vitamin D deficiency is vitamin D (calciferol). What is measured in the blood stream as the best marker of vitamin D status is not vitamin D, but 25OHD. It is time to reconsider the terminology we use and move forward into the twenty-first century with precise and selfexplanatory terms.

\section{Calcium Deprivation: Concept and Clinical Spectrum}

\section{The Concept of Calcium Deprivation}

Calcium and phosphate are the main mineral ions responsible for bone stiffness. Calcitriol is the main supplier of these bone minerals, which are ingested daily, by increasing their intestinal absorption. Calcitriol therefore cannot do its job in individuals who have no oral intake. Combined or in isolation, low dietary calcium supply and low vitamin D status cause calcium deprivation, which is quickly sensed by the calcium sensing receptor in the parathyroid's chief cells, leading to increased release of parathyroid hormone (PTH) [23]. This secondary hyperparathyroidism stimulates osteoclastic bone resorption with the aim to release stored bone minerals. This compensation mechanism works well to maintain normal serum calcium levels, but sustained hyperparathyroidism has two main complications: (1) structural damage to bone and (2) decreased renal reabsorption of phosphate. Eventually, this compensation will fail as the calcium stored in bone will ultimately be depleted, leading to hypocalcaemic complications (seizures, tetany and cardiomyopathy) and late hypophosphataemic complications (nutritional rickets, osteomalacia and muscle weakness) unless more calcium is made available to restore eucalcemia and normalise PTH levels. Hypophosphataemia increases the formation of poorly mineralised osteoid (osteomalacia) alongside a rise in serum alkaline phosphatase (ALP) and causes the growth plate abnormality known as rickets. The concept of calcium deprivation and its evolution into rickets and osteomalacia is depicted in Fig. 1. Because secondary hyperparathyroidism maintains normal serum calcium levels until compensation fails, serum calcium is a poor marker of calcium status, whereas 25OHD is currently regarded as the best marker of vitamin D status. Therefore, the earliest biochemical signs of clinically relevant calcium deprivation are increased serum PTH and decreased urinary calcium levels; both are sensitive markers of total body calcium deprivation and will provide an indicator of both the severity and duration of the vitamin D deficient or the dietary calcium deficient state. 
Fig. 1 Stages of calcium deprivation leading to nutritional rickets and osteomalacia

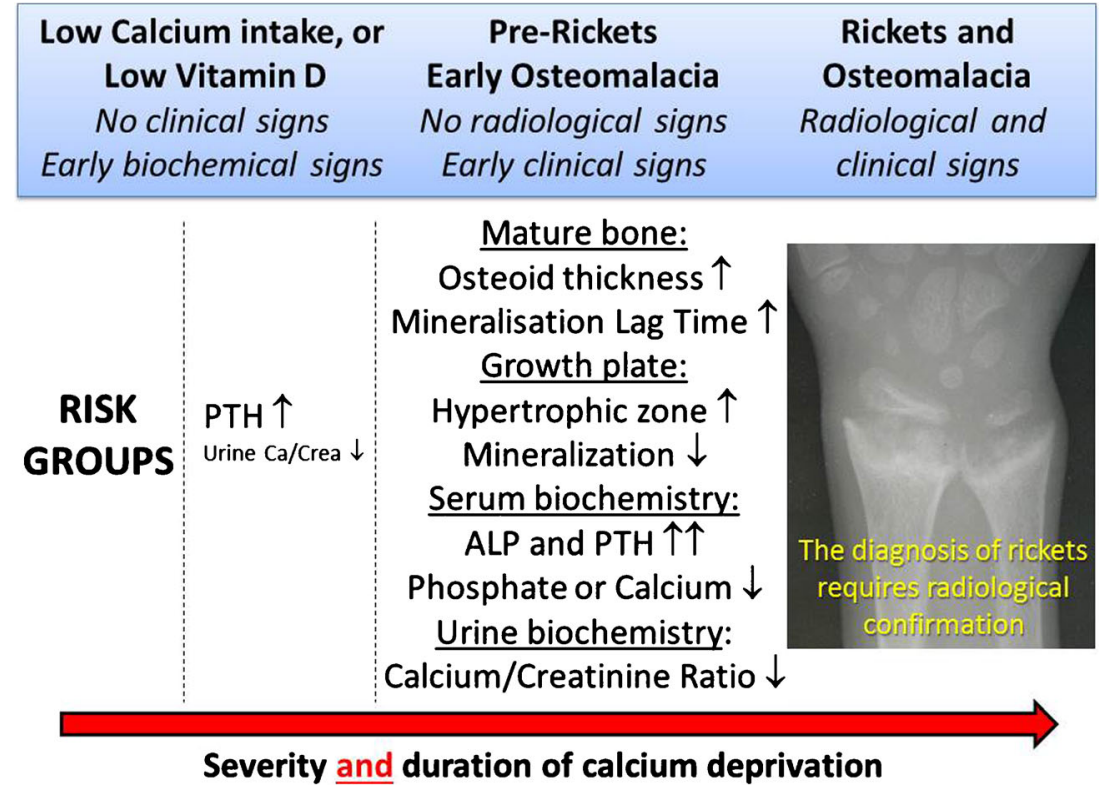

\section{The Clinical Spectrum of Calcium Deprivation from Conception to Old Age}

The role of vitamin D as a mineral supplier in normal bone and dental development is well established [24]. Maternal calcium deprivation rarely affects the foetus who is protected by drawing minerals from the mother through increased maternal intestinal mineral absorption and bone resorption [25]. However, low maternal vitamin D reserve is always passed on to the foetus. Hence, vitamin D supplementation needs to start at birth to protect the neonate from developing complications from calcium deprivation, including rickets, during the rapid infantile growth [4•]. Depending on the duration and severity of maternal vitamin D deficiency, the unsupplemented infant is at high risk of presenting in the first few days or months of life with hypocalcaemic complications. These include seizures, tetany $[7 \bullet, 26,27]$ and dilated cardiomyopathy which may result in cardiac failure and death $[5$, $6,28]$. Hypophosphataemic complications include muscle weakness leading to hypotonia and delayed development, craniotabes, large fontanelles and bony deformities which usually present in the first 18 months of life [29, 30]. Only severe, long-standing calcium deprivation during pregnancy will manifest in the newborn skeleton at birth, referred to as congenital rickets [31]. If undiagnosed, there is a concern that hypocalcaemia, cardiomyopathy and rickets will contribute to or cause infant mortality. A retrospective analysis post-mortem identified hypocalcaemia contributing to death in 3 of 52 children; two had cardiomyopathy and one had hypocalcaemic seizures. All three patients were of Black ethnic origin and also had histological and radiological evidence of rickets [8•]. Another UK post-mortem study highlighted that a significant proportion $(76 \%)$ of children with unexplained sudden death $(n=25)$ had suboptimal vitamin D levels, of whom $69 \%$ had histological signs of rickets [9]. In infants and young children, rickets remains a radiological diagnosis that needs to be confirmed by taking a knee Xray.

Older children can present with motor delay, proximal myopathy [32] and dental complications [33]. As NR frequently manifests in phases of rapid growth, a second peak in incidence of hypocalcaemic seizures and NR is seen in adolescence $[3,7 \cdot]$. Diagnosis is based on clinical findings (long bone deformities, enlargement of wrists and costochondral junctions), typical biochemical abnormalities (increased ALP and PTH) and radiological changes of rickets (cupping, splaying and fraying of metaphyses, widened growth plates and low bone mass). In older children and specifically adolescents with less rapid growth, the radiological changes of the growth plate typical for rickets may not be visible, and equally, osteomalacia cannot be diagnosed on X-rays.

Osteomalacia in girls can cause pelvic deformities and lead to obstructed labour later in life [34]. Elderly and institutionalised individuals develop muscle weakness which manifests as increased falls and fractures, the incidence of which is reduced with calcium and vitamin D supplements [35].

Manifestations of all these complications of calcium deprivation throughout life demonstrate that dietary calcium and vitamin D deficiency are widespread in society, particularly among high-risk groups. 


\section{Sufficient Dietary Calcium and Vitamin D, and Treatment of Rickets}

\section{How Much Vitamin D and Dietary Calcium is Enough?}

The 'optimal' serum 25OHD concentration remains controversial, with definitions ranging from $>50$ to $>100 \mathrm{nmol} / \mathrm{L}$ (20 to $40 \mu \mathrm{g} / \mathrm{L}$ ) [36]. Multiple paediatric and endocrine societies have independently made recommendations for deficient and sufficient serum 25OHD levels [37-41]. Disagreement among societies [42] creates confusion among healthcare professionals, researchers and the general public. A good part of the confusion stems from the ignorance of vitamin D enthusiasts towards the role of dietary calcium intake and PTH in the pathophysiology of rickets and osteomalacia. To provide clarification on this issue, representatives from 11 international scientific organisations came together in 2014 to create evidence-based Global Consensus Recommendations on Prevention and Management of Nutritional Rickets [13••, 14]. These papers treat calcium intake and vitamin $D$ status equally and define each by a three-stage category as sufficient, insufficient and deficient. The term 'sufficiency' in the consensus was based on minimum calcium intakes and 25OHD levels required to prevent NR (Table 1).

\section{Management of NR}

The Global Consensus group recommended doses of vitamin $\mathrm{D}$ and calcium for treatment of NR [13••, 14]. Evidence indicates that the oral route is preferred to parenteral (Stoss therapy) due to more rapid restoration of 25OHD levels. Both vitamin D2 and D3 are equally effective for daily treatment, whilst D3 with a longer half-life is preferred for single dose treatment. All children with NR should be treated with vitamin $\mathrm{D}$ for a minimum of 3 months with a daily dose of at least $2000 \mathrm{IU}(50 \mu \mathrm{g})$ if aged $<12$ months, 3000-6000 IU (50$150 \mu \mathrm{g})$ if aged 12 months-12 years, and $6000 \mathrm{IU}(150 \mu \mathrm{g})$ if aged $>12$ years $[13 \bullet \bullet, 14]$. Single high dose (Stoss therapy) can be used in resource-limited settings in infants aged $>3$ months: 50,000 IU $(1250 \mu \mathrm{g})$ for 3 months -12 months of age, $150,000 \mathrm{IU}(3750 \mu \mathrm{g})$ for children aged 12 months-

Table 1 Global consensus definitions of vitamin D status and dietary calcium intake $[13 \bullet \bullet, 14]$

\begin{tabular}{lll}
\hline & Serum 25OHD levels & Daily calcium intake \\
\hline Deficient & $>50 \mathrm{nmol} / \mathrm{L}$ & $>500 \mathrm{mg}$ \\
Insufficient & $30-50 \mathrm{nmol} / \mathrm{L}$ & $300-500 \mathrm{mg}$ \\
Sufficient & $<30 \mathrm{nmol} / \mathrm{L}$ & $<300 \mathrm{mg}$ \\
Evidence grade & $1 \oplus \oplus \oplus^{\mathrm{a}}$ & $1 \oplus \oplus^{\mathrm{b}}$ \\
\hline
\end{tabular}

${ }^{a}$ Strong recommendation with high quality evidence

${ }^{\mathrm{b}}$ Strong recommendation with moderate quality evidence
12 years, and $300,000 \mathrm{IU}(7500 \mu \mathrm{g})$ if aged $>12$ years $[13 \bullet \bullet$, 14]. All individuals should also receive concomitant calcium (minimum $500 \mathrm{mg} /$ day) as supplements or via diet. All treatment should be followed by lifelong vitamin D supplements, since the underlying risk (ethnicity, culture and sunlight exposure) is unlikely to change.

\section{Prevention and Public Health}

\section{Identification of Risk Groups is Straightforward}

In developed countries, the prevalence of NR is several hundred-fold higher in dark-skinned immigrants compared to native populations [12••]. This means conditions that are rare in the host country are common in ethnic minorities. The underlying endemic vitamin D deficiency in these ethnic risk groups is exemplified by a population-based study in 2225 school children and 830 adults in Saudi Arabia, demonstrating that $92 \%$ of girls and $79 \%$ of boys, and $75 \%$ and $74 \%$ of adult women and men, respectively, had 25OHD levels below $50 \mathrm{nmol} / \mathrm{L}(20 \mu \mathrm{g} / \mathrm{L})[43 \cdot]$. In developed countries, there has been a steady increase in the proportion of dark-skinned populations (both immigrant and resident) which mirror the trends in NR [12••]. Healthcare authorities should identify the specific risk groups to target intervention which is a straightforward task as skin colour, ethnicity and culture are visible factors; similarly, information on dairy intake as the main source of dietary calcium can be easily obtained [44]. Healthcare providers should recognise the need to supplement the highrisk individuals upon arrival into the country [12••], and supplementation should be incorporated into immigrant/refugee health assessment policies. The mounting evidence on endemic calcium deprivation and NR in risk groups precludes the need for routine 25OHD measurement in asymptomatic individuals; the consensus group therefore recommends lifelong supplementation in high-risk groups [13••, 14].

In developing countries populated by high-risk ethnic groups, the failure, or non-existence, of vitamin D supplementation policies are main contributors to the rise in NR despite abundant sunshine [18• 45-47]. A recent study from Egypt reported a high incidence (13.1\%) of rachitic genu varum in children aged 2-4 years [48]. The study reported the following risk factors to be associated with the development of NR: low socioeconomic status, insufficient family income, poor housing conditions, lack of sunlight exposure due to cultural practices, sole breast feeding and inadequate supplementation of vitamin D in children and pregnant women [48].

\section{Effective Prevention}

NR and osteomalacia are fully preventable. Universal supplementation of infants [49], supplementing pregnant women 
[50], promoting vitamin uptake [51] and also food fortification with vitamin $\mathrm{D}$ and calcium to prevent fractures in elderly [52] have been proven cost-effective. However, there is limited data on vitamin D fortification and how fortification programmes compare to population supplementation programmes [53].

The global consensus recommends the following vitamin D supplements for prevention of NR and osteomalacia [13••, 14]:

- $400 \mathrm{IU}(10 \mu \mathrm{g})$ daily for all infants regardless of mode of feeding, from birth to a minimum of 12 months of age.

- $600 \mathrm{IU}(15 \mu \mathrm{g})$ daily during pregnancy (alongside iron and folic acid).

- 600 IU daily lifelong in risk groups, including individuals with dark skin, full body clothing, limited sun exposure either due to geographic location, limited outdoor activity or restricted mobility, low socioeconomic background and poor diet. Individuals at risk should also meet the daily minimum requirement for sufficient calcium intake (Table 1).

Effective prevention programmes depend on feasible, monitored and mandatory implementation strategies.

\section{Monitored Supplementation of Pregnant Women}

Low socioeconomic status, covered clothing and lack of supplementation contribute to high prevalence of vitamin D deficiency in pregnancy [54]. Congenital rickets and postnatal hypocalcaemic seizures are reported in risk groups in both developed and developing countries [27, 55, 56]. Poor maternal vitamin D status affects the foetus and the newborn. In a large Italian study, $76 \%$ of newborns of dark-skinned migrant women had $25 \mathrm{OHD}$ levels below $25 \mathrm{nmol} / \mathrm{L}(10 \mu \mathrm{g} / \mathrm{L})$, compared to $38 \%$ of newborns of native Italian women [57•]. Although the World Health Organisation is yet to provide stronger recommendations, it confirms that vitamin D supplementation during pregnancy is necessary to prevent NR in the newborn [58]. The global consensus group recommends that monitored vitamin D supplementation should be included in antenatal care programmes $[13 \bullet \bullet, 14]$.

\section{Universal Supplementation of Infants Regardless of Mode of Feeding}

The amount of vitamin D available in breast milk but also infant formula milk is insufficient to prevent NR; even formula-fed infants can present with symptomatic deficiency in the first few months of life $[7 \cdot, 59,60]$ if born to deficient mothers. In a recent survey of vitamin D supplementation policies across Europe, we found that universal supplementation, currently practised by $79 \%(23 / 29)$ of countries was significantly $(p=0.007)$ associated with good adherence to supplements [61]. The recommended dose of $400 \mathrm{IU} /$ day $(10 \mu \mathrm{g})$ is safe also in formula-fed infants. Toxicity is usually related to errors in manufacturing, formulation or prescription $[62,63]$. A Dutch study pointed out the theoretical risk of exceeding the upper limit of vitamin D consumption in infants aged 7-11 months from a combination of infant formula, recommended supplements (10 $\mu \mathrm{g} /$ day) and fortified food [64], based on the upper limit of $1000 \mathrm{IU} /$ day $(25 \mu \mathrm{g})$, recommended by the European Food Safety Authority. However, none of the infants in the study exceeded the upper limit recommended by the Institute of Medicine which is $1500 \mathrm{IU} /$ day $(37.5 \mu \mathrm{g})$ [40].

\section{Supplementation Beyond the First Year of Life}

The duration of childhood supplementation varies widely across Europe [61]. Assessment of daily intakes at 18 months and 3.5 years of age in 755 children in the UK showed low daily intakes of vitamin $\mathrm{D}$ and calcium [65]. The incidence of NR rises beyond the recommended age of infant supplementation [3, 66, 67], especially in dark-skinned (immigrant or resident) individuals. Hence, national policies should ensure that the daily requirement of vitamin $\mathrm{D}$ beyond the first year of life is met through supplementation or fortification [68•]. In the absence of food fortification, policy makers should identify the high-risk ethnic groups and recommend lifelong supplementation (Table 2).

\section{Identifying Successful and Sustainable Implementation Strategies}

Although most developed countries have vitamin D supplementation policies in place, some countries lack successful implementation strategies. Recent studies from Canada and New Zealand reported that none of the individuals with NR had received vitamin D supplements for rickets prevention despite the presence of national recommendations $[69,70]$. Similarly, $85 \%$ of British parents are unaware of the need for infant vitamin D supplementation for their baby despite existing policy [71]. There is overwhelming evidence that infant vitamin D supplementation improves 25OHD concentrations [72] and prevents NR [73]. We recently studied policy features and implementation strategies that influence good adherence to supplements ( $\geq 80 \%$ of infants at 1 year) [61]. Although $97 \%$ of European countries studied $(n=29)$ had a national supplementation policy in place, policy features varied. Efficient implementation strategies such as monitoring adherence at child health surveillance visits $(p=0.001)$, universal supplementation $(p=0.007)$, providing information to families at discharge from neonatal units $(p=0.02)$ and financial family support ( $p=0.005$ ) were lacking in countries with low adherence $(<50 \%$ of infants). Moreover, countries with 
Table 2 Summary of revised concepts

\begin{tabular}{ll}
\hline Topic & Revised concepts \\
\hline Calcitriol is not vitamin D & Like cholesterol is biochemically modified by the human body to form \\
& active steroid hormones, vitamin D is modified to form the hormone \\
& calcitriol. Calcitriol acts on the calcitriol receptor (VDR), whilst vitamin \\
& D and 25OHD are biologically inert. \\
Calcium deprivation and its & and/or low vitamin D. Calcium deprivation has hypocalcaemic \\
complications & (seizures, tetany and cardiomyopathy) and late hypophosphataemic \\
& (rickets, osteomalacia and muscle weakness) complications. \\
What to measure and how to & 25OHD is a good marker of vitamin D status but serum calcium is a poor \\
make a diagnosis & marker of calcium status. Consistent and early biochemical markers for \\
& diagnosis of rickets and osteomalacia are elevations in serum ALP and \\
High prevalence in risk groups & PTH. The diagnosis of rickets requires radiological confirmation. \\
& NR/osteomalacia is less common in the white population but a common \\
disease in ethnic risk groups with dark skin or cultural full body clothing, & including refugees. These groups require lifelong supplementation \\
and/or food fortification programmes. \\
Measuring 25OHD and \\
indication for \\
supplementation
\end{tabular}

high adherence adopted more policy factors and implementation strategies compared to moderate and low adherence countries $(p<0.001)[61]$.

Policy makers should clarify the responsibilities of healthcare professionals delivering the policy [4•] such as providing information on prevention, prescribing supplements and checking adherence at child health surveillance or immunisation visits. Interestingly, free supply of vitamins alone does not automatically enhance adherence and participation $[74,75]$.

\section{Health Promotion}

In 2008, Turkey reduced the incidence of NR by visiting primary health stations throughout the country and supplying free vitamins [73]. However, a recent survey demonstrated persistent poor knowledge among healthcare professionals of existing prevention programmes in Turkey [76]. Similar health promotion campaigns have proven successful [77, 78]; however, the results are not sustained [3]. Therefore, more sustainable delivery of information to both healthcare professionals and target groups is essential. The global consensus group recommends integration of vitamin D supplementation into antenatal and infant child care passport programmes [13••, 14]. Such programmes should dictate monitoring of adherence and prescription of supplements at all prenatal and child health surveillance visits. Bolus vitamin $\mathrm{D}$ doses alongside vaccinations has been done successfully [79].

\section{Food Fortification with Vitamin D or Calcium}

Health benefits of food fortification with micronutrients, including vitamin D, are well established [80]. Currently, most European countries follow voluntary fortification [81]; however, evidence from Canada and the USA suggests that mandatory fortification improves vitamin D uptake at the population level [82]. Fortification should not be restricted to dairy products due to its limited consumption in certain risk groups [83]; fortification of a variety of food sources is more beneficial [81]. Countries with established mandatory fortification are now adopting novel approaches such as 'bio-addition' which involves fortification of staple food through addition of vitamin D-rich food to animal feed during production or manipulation of food post-harvest or pre-processing [82]. In order to address malnutrition and the multiple micronutrient deficiencies across the globe, it is crucial that governments and international agencies look beyond single micronutrient deficiencies and initiate mandatory fortification [84, 85]. For regions with traditionally low dietary calcium, e.g. Africa [86] 
and India [87], the global consensus group recommended use of calcium supplement from indigenous sources [13••, 14].

\section{Areas Warranting Further Research}

\section{The True Prevalence of NR and Osteomalacia}

The true prevalence of NR and osteomalacia across the globe remains unknown [88]. Studies are urgently needed to establish their prevalence at a population level, in particular in areas where such data would matter most for public health, as in Africa, the Indian subcontinent and the Middle East. Most population screening studies to date have used clinical signs, biochemical markers (raised ALP and PTH, low calcium, low 25OHD) and radiological signs to define rickets, either in isolation or in combination [89]. Further studies are warranted to identify the most appropriate biochemical marker for screening of NR. Ultimately, the histological presence of osteomalacia defines the presence of pathology, and research should focus on how histology relates to levels of calcium deprivation, elevations of ALP and PTH, radiological signs of rickets and fracture risk (Fig. 1). Until a reliable screening tool is available, NR should be considered a reportable disease by health authorities.

\section{Efficacy and Safety of Targeted Intermittent Oral Supplementation and Fortification Programmes}

A lot more work needs to be done on trials designed to demonstrate safety and efficacy of community-based, targeted supplementation programmes, including adherence and health economics. Similarly, food fortification programmes, ideally incorporating multiple nutrients such as folic acid, require large scale trials.

\section{Vitamin D Deficiency and Non-accidental Injuries}

The role of vitamin D deficiency (with absent radiological signs of rickets) in bone fragility is much debated in the context of non-accidental injuries $[90,91]$. The state of pre-rickets/osteomalacia (Fig. 1) is only identified on bone histology. It has been demonstrated that the pickup rate of biopsy proven rickets by radiologists is poor $[8 \cdot, 9,92]$. NR and osteomalacia, as hypophosphataemic complications, occur late in the time course of calcium deprivation, and thus radiological signs occur very late. It is only reasonable to assume that histological and histomorphometric changes precede $\mathrm{x}$-ray changes [4•]. No studies have tested bone fragility in the setting of low 25OHD levels (with or without ALP/PTH elevation) with normal radiology of the growth plate. Therefore, despite association studies [93-95], there is currently insufficient evidence to conclude that the child is susceptible to fractures in this setting. Only a well-designed bone biopsy study would help answer this question.

\section{Undiagnosed NR and Mortality}

Studies describe incidental cardiomyopathy and histological evidence of NR in Sudden Unexpected Death in infancy and childhood $[8 \cdot, 9]$. Prolonged severe vitamin D deficiency leads to hypocalcaemia which can cause sudden death in infants [8•]. The prevalence of insufficient 25OHD levels in undiagnosed cases of sudden infant death at post-mortem is high [9]. Further, large scale, prospective studies are required to confirm the true prevalence of NR and osteomalacia, which includes establishing the feasibility of measuring $25 \mathrm{OHD}$, and markers of other micronutrient deficiencies, post-mortem.

\section{Genetic Polymorphisms and Best Marker of Vitamin D Status}

Polymorphisms in genes encoding key enzymes (i.e. CYP3A4, CYP24 and CYP27B1) and proteins that affect the circulating concentrations of vitamin D metabolites have been described [96]. Polymorphisms in the genes encoding vitamin D binding protein help to explain the increased susceptibility of African American infants and toddlers to vitamin D deficiency [97]. However, only less than $5 \%$ of the variations in serum $25 \mathrm{OHD}$ concentrations are explained by genetic variants [96] with major determinants still being lifestyle factors such as exposure to sunlight and dietary habits. Vitamin D status is universally determined by $250 \mathrm{OHD}$ measurements; however, the search for the ideal biochemical marker continues [98].

\section{Conclusions}

The global rise in a preventable disease like NR in the twentyfirst century is unacceptable. NR is a common disease in highrisk groups worldwide, even in high income countries, highlighted by refugee crises and changing population demographics. However, fair-skinned people are not exempt from risk. The global consensus recommendations $[13 \bullet \bullet, 14]$ provide guidance both for clinicians and policy makers on the prevention of rickets, and infants, pregnant women and dark-skinned individuals should be at the core of any policies. In addition to implementing successful supplementation programmes for these risk groups, mandatory food fortification should be considered by government bodies and international agencies as a means to improve nutritional vitamin D and/or calcium status at the population level. Areas that warrant further public health research include the ideal marker for screening of NR and osteomalacia as well as for vitamin D status, intermittent oral supplementation administered by 
healthcare providers and the relationship between early signs of a mineralization defect (i.e. bone biochemical or histological findings) on bone fragility and on infant and child mortality.

\section{Compliance with Ethical Standards}

Conflict of Interest Wolfgang Högler and Suma Uday declare no conflict of interest.

Human and Animal Rights and Informed Consent This article does not contain any studies with human or animal subjects performed by any of the authors.

Open Access This article is distributed under the terms of the Creative Commons Attribution 4.0 International License (http:// creativecommons.org/licenses/by/4.0/), which permits unrestricted use, distribution, and reproduction in any medium, provided you give appropriate credit to the original author(s) and the source, provide a link to the Creative Commons license, and indicate if changes were made.

\section{References}

Papers of particular interest, published recently, have been highlighted as:

- Of importance

•. Of major importance

1. Prentice A. Nutritional rickets around the world. J Steroid Biochem Mol Biol. 2013;136(1):201-6.

2.• Goldacre M, Hall N, Yeates DGR. Hospitalisation for children with rickets in England: a historical perspective. Lancet. 2014;383(9917):597-8. Hospitalisation rates due to rickets in England increased over five decades alongside a rise in proportion of dark-skinned at-risk population.

3. Ahmed SF, Franey C, McDevitt H, Somerville L, Butler S, Galloway P, et al. Recent trends and clinical features of childhood vitamin D deficiency presenting to a children's hospital in Glasgow. Arch Dis Child. 2011;96(7):694-6.

4. Högler W. Complications of vitamin D deficiency from the foetus to the infant: one cause, one prevention, but who's responsibility? Best Pract Res Clin Endocrinol Metab. 2015;29(3):385-98. Review introduces the concept of calcium deprivation, highlights risk groups and the role policy makers in assigning responsibilites to healthcare professionals in prevention of NR

5. Sanyal D, Raychaudhuri M. Infants with dilated cardiomyopathy and hypocalcemia. Indian J Endocrinol Metab. 2013;17(Suppl 1): S221-3.

6. Maiya S, Sullivan I, Allgrove J, Yates R, Malone M, Brain C, et al. Hypocalcaemia and vitamin D deficiency: an important, but preventable, cause of life-threatening infant heart failure. Heart. 2008;94(5):581-4.

7. Basatemur E, Sutcliffe A. Incidence of hypocalcemic seizures due to vitamin D deficiency in children in the United Kingdom and Ireland. J Clin Endocrinol Metab. 2015;100(1):E91-5. Paper demonstrates that hypocalcaemic complications of NR are a significant burden in the UK

8. Scheimberg I, Perry L. Does low vitamin D have a role in pediatric morbidity and mortality? An observational study of vitamin D in a cohort of 52 postmortem examinations. Pediatr Dev Pathol.
2014;17:455-64. Paper explores the role of undiagnosed rickets in sudden unexpected child deaths in the setting of low 250HD levels post-mortem

9. Cohen MC, Offiah A, Sprigg A, Al-Adnani M. Vitamin D deficiency and sudden unexpected death in infancy and childhood: a cohort study. Pediatr Dev Pathol. 2013;16(4):292-300.

10. Priemel M, Domarus C, Von Klatte TO, Kessler S, Schlie J, Meier $\mathrm{S}$, et al. Bone mineralization defects and vitamin D deficiency: histomorphometric analysis of iliac crest bone biopsies and circulating 25-hydroxyvitamin D in 675 patients. J Bone Miner Res. 2010;25(2):305-12. Paper demonstrates a high prevalance of histological osteomalacia in the setting of low 25OHD levels post-mortem in the elderly, highlighting the need for lifelong supplementation

11. Cashman KD, Dowling KG. Vitamin D deficiency in Europe: pandemic? Am J Clin Nutr. 2016;103(4):1033-44. Paper highlights the high prevalance of vitamin $D$ deficiency across Europe in atrisk populations

12.• Thacher TD, Pludowski P, Shaw NJ, Mughal MZ, Munns CF, Högler W. Nutritional rickets in immigrant and refugee children. Public Health Rev. 2016;37(3):1-10. Paper demonstrates the high prevalance of nutritional rickets in at-risk populations across developed countries and calls for robust prevention programs.

13.• Munns CF, Shaw N, Kiely M, Specker BL, Thacher TD, Ozono K, et al. Global consensus recommendations on prevention and management of nutritional rickets. Horm Res Paediatr. 2016;85(2):83106. The evidence-based consensus from 11 international societies for prevention and management of NR, recognises the equal role of vitamin $D$ deficiency and dietary calcium deficiency in the causation of NR, provides clear guidance to clinicians managing NR and to policy makers for designing preventative strategies

14. Munns CF, Shaw N, Kiely M, Specker BL, Thacher TD, Ozono K, et al. Global consensus recommendations on prevention and management of nutritional rickets. J Clin Endocrinol Metab. 2016;101(2):394-415.

15. Pettifor JM. Nutritional Rickets. Pediatric Bone: Biology \& Diseases. 2003. p. 541-65.

16. Tiosano D, Hochberg Z. Hypophosphatemia: the common denominator of all rickets. J Bone Miner Metab. 2009;27(4):392-401.

17. Pettifor JM. Nutritional rickets: pathogenesis and prevention. Pediatr Endocrinol Rev Rev. 2013;10(Suppl 2):347-53.

18. Aggarwal V, Seth A, Aneja S, Sharma B, Sonkar P, Singh S, et al. Role of calcium deficiency in development of nutritional rickets in Indian children: a case control study. J Clin Endocrinol Metab. 2012:97(10):3461-6. This case control study demonstrates that dietary calcium deficiency is the main cause of NR in countries with abundant sunshine

19. Fischer PR, Rahman A, Cimma JP, Kyaw-Myint TO, Kabir ARML, Talukder K, et al. Nutritional rickets without vitamin D deficiency in Bangladesh. J Trop Pediatr. 1999;45(5):291-3.

20. Al-Atawi MS, Al-Alwan IA, Al-Mutair AN, Tamim HM, AlJurayyan NA. Epidemiology of nutritional rickets in children. Saudi J Kidney Dis Transplant. 2009;20(2):260-5.

21. Thacher TD, Fischer PR, Isichei CO, Zoakah AI, Pettifor JM. Prevention of nutritional rickets in Nigerian children with dietary calcium supplementation. Bone. 2012;50(5):1074-80.

22. Gawlik A, Gepstein V, Rozen N, Dahan A, Ben-Yosef D, Wildbaum $\mathrm{G}$, et al. Duodenal expression of 25 hydroxyvitamin D3-1 $\alpha$-hydroxylase is higher in adolescents than in children and adults. J Clin Endocrinol Metab. 2015;100(10):3668-75.

23. Atapattu N, Shaw N, Högler W. Relationship between serum 25hydroxyvitamin $\mathrm{D}$ and parathyroid hormone in the search for a biochemical definition of vitamin $\mathrm{D}$ deficiency in children. Pediatr Res. 2013;74(5):552-6. 
24. EFSA (European Food Safety Authority) Scientific opinion on the substantiation of a health claim related to vitamin D and contribution to normal bone and tooth development pursuant to Article 14 of Regulation (EC) No 1924/2006. EFSA. 2014.

25. Kovacs CS. Maternal vitamin D deficiency: fetal and neonatal implications. Semin Fetal Neonatal Med. 2013;18(3):129-35.

26. Cesur Y, Yuca SA, Kaya A, Yilmaz C, Bay A. Vitamin D deficiency rickets in infants presenting with hypocalcaemic convulsions. West Indian Med J. 2013;62(3):201-4.

27. Thomas TC, Smith JM, White PC, Adhikari S. Transient neonatal hypocalcemia: presentation and outcomes. Pediatrics. 2012;129(6): e1461-7.

28. Fabi M, Gesuete V, Petrucci R, Ragni L. Dilated cardiomyopathy due to hypocalcaemic rickets: is it always a reversible condition. Cardiol Young. 2013;23(5):769-72.

29. Shaw NJ, Mughal MZ. Vitamin D and child health part 1 (skeletal aspects). Arch Dis Child. 2013;98(5):363-7.

30. Robinson PD, Högler W, Craig ME, Verge CF, Walker JL, Piper $\mathrm{AC}$, et al. The re-emerging burden of rickets: a decade of experience from Sydney. Arch Dis Child. 2006;91(7):564-8.

31. Erdeve Ö, Atasay B, Arsan S, Şiklar Z, Öcal G, Berberoğlu M. Hypocalcemic seizure due to congenital rickets in the first day of life. Turk J Pediatr. 2007;49(3):301-3.

32. Fluss J, Kern I, de Coulon G, Gonzalez E, Chehade H. Vitamin D deficiency: a forgotten treatable cause of motor delay and proximal myopathy. Brain and Development. 2014;36(1):84-7.

33. Davit-Béal T, Gabay J, Antoniolli P, Masle-Farquhar J, Wolikow M. Dental complications of rickets in early childhood: case report on 2 young girls. Pediatrics. 2014;133(4):e1077-81.

34. Konje JC, Ladipo OA. Nutrition and obstructed labor. Am J Clin Nutr. 2000;72(1 SUPPL):291s-7s.

35. Lamberg-Allardt C, Brustad M, Meyer HE, Steingrimsdottir L. Vitamin D - a systematic literature review for the 5th edition of the Nordic nutrition recommendations. Food Nutr Res. 2013;57: 22671.

36. Prentice A. Vitamin D deficiency: a global perspective. Nutr Rev. 2008;66(10 Suppl.2):S153-64.

37. Saggese G, Vierucci F, Boot AM, Czech-Kowalska J, Weber G, Camargo CA, et al. Vitamin D in childhood and adolescence: an expert position statement. Eur J Pediatr. 2015;174(5):565-76.

38. Arundel P, Ahmed S, Allgrove J, Bishop NJ, Burren C, Jacobs B, et al. British Paediatric and Adolescent Bone Group's position statement on vitamin D deficiency. BMJ. 2012;345:e8182.

39. Paxton G, Teale GR, Nowson C, Mason RS, McGrath JJ, Thompson MJ, et al. Vitamin D and health in pregnancy, infants, children and adolescents in Australia and New Zealand: a position statement. Med J Aust. 2013;198(3):142-3.

40. Institute of Medicine. Dietary reference intakes for calcium and vitamin D. The National Academias press. 2011

41. Holick MF, Binkley NC, Bischoff-ferrari HA, Gordon CM, Hanley DA, Heaney RP, et al. Evaluation, treatment, and prevention of vitamin D deficiency: an Endocrine Society clinical practice guideline. J Clin Endocrinol Metab. 2011;96(7):1911-30.

42. Rosen CJ, Abrams SA, Aloia JF, Brannon PM, Clinton SK, Durazo-Arvizu RA, et al. IOM committee members respond to endocrine society vitamin D guideline. J Clin Endocrinol Metab. 2012;97(4):1146-52.

43. Al-Daghri NM, Al-Saleh Y, Aljohani N, Alokail M, Al-Attas O, Alnaami AM, et al. Vitamin D deficiency and cardiometabolic risks: a juxtaposition of Arab adolescents and adults. PLoS One. 2015;10(7):e0131315. Study highlights the high prevalence of vitamin $D$ deficiency in a society dominated by an ethnic and cultural at-risk population

44. Nordblad M, Graham F, Mughal MZ, Padidela R. Rapid assessment of dietary calcium intake. Arch Dis Child. 2016;101(7):634-6.
45. Pettifor JM, Ross P, Wang J, Moodley G, Couper-Smith J. Rickets in children of rural origin in South Africa: is low dietary calcium a factor? J Pediatr. 1978;92(2):320-4.

46. Eyberg CJ, Pettifor JM, Moodley G. Dietary calcium intake in rural black South African children. The relationship between calcium intake and calcium nutritional status. Hum Nutr Clin Nutr. 1986;40(1):69-74.

47. Okonofua F, Gill DS, Alabi ZO, Thomas M, Bell JL, Dandona P. Rickets in Nigerian children: a consequence of calcium malnutrition. Metabolism. 1991;40(2):209-13.

48. Bishay SNG, El-Sherbini MHA, Azzam AA, Lotfy AA. The open orthopaedics journal incidence and risk factors of rachitic genu varus in preschool children in a paediatric health institute in Egypt as one of the developing countriesss. Open Orthop J 2016;10:412419.

49. McGee E. Prevention of rickets and vitamin D deficiency in Birmingham: the case for universal supplementation. National Health Service: Birmingham; 2010.

50. Kamudoni P, Poole C, Davies SJ. An estimate of the economic burden of vitamin D deficiency in pregnant women in the United Kingdom. Gynecol Endocrinol. 2016;32(8):592-7.

51. Filby A, Lewis L, Taylor M. An economic evaluation of interventions to improve the uptake of vitamin D supplements in England and Wales. PH56. National Institute for Health and Care Excellence. York Health Economics Consortium. 2014.

52. Sandmann A, Amling M, Barvencik F, Konig H-H, Bleibler F. Economic evaluation of vitamin D and calcium food fortification for fracture prevention in Germany. Public Health Nutr. 2015:1-10.

53. Aguiar M, Andronis L, Pallan M, Högler W, Frew E. Preventing vitamin D deficiency (VDD): a systematic review of economic evaluations. Eur J Pub Health. 2017;27(2):292-301.

54. Parlak M, Kalay S, Kalay Z, Kırecci A, Guney O, Koklu E. Severe vitamin $\mathrm{D}$ deficiency among pregnant women and their newborns in Turkey. J Matern Neonatal Med. 2015;28(5):548-51.

55. Paterson CR, Ayoub D. Congenital rickets due to vitamin D deficiency in the mothers. Clin Nutr. 2015;34(5):793-8.

56. Elidrissy ATH. The return of congenital rickets, are we missing occult cases? Calcif Tissue Int. 2016;99(3):227-36.

57. Cadario F, Savastio S, Magnani C, Cena T, Pagliardini V, Bellomo $\mathrm{G}$, et al. High prevalence of vitamin D deficiency in native versus migrant mothers and newborns in the North of Italy: a call to act with a stronger prevention program. PLoS One. 2015;10(6): e0129586. Paper demonstrates the high prevalence of vitamin $D$ deficiency in migrant women and newborns, and calls for prevention programs in at-risk pregnant women and their offsprings

58. Schoenmakers I, Pettifor JM, Peña-Rosas JP, Lamberg-Allardt C, Shaw N, Jones KS, et al. Prevention and consequences of vitamin D deficiency in pregnant and lactating women and children: a symposium to prioritise vitamin D on the global agenda. J Steroid Biochem Mol Biol. 2015;164:156-60.

59. Gross ML, Tenenbein M, Sellers EAC. Severe vitamin D deficiency in 6 Canadian first nation formula-fed infants. Int J Circumpolar Health. 2013;72(1):20244.

60. Solís M, De Alvaré A, Yebra J, García Pose A, Martínez A. Nutritional rickets in a bottle-fed 2 months old baby. Horm Res Paediatr. 2015;84:355.

61. Uday S, Kongjonaj A, Tulchinsky T, Högler W. Characteristics of Vitamin D supplementation programs for the prevention of rickets in infants and young children in Europe: Factors influencing compliance. BSPED. 2016. p. ISSN 1479-6848 (online). Available from: http:// www.endocrine-abstracts.org/ea/0045/BSPED2016AbstractBook.pdf

62. Vogiatzi MG, Jacobson-Dickman E, DeBoer MD. Vitamin D supplementation and risk of toxicity in pediatrics: a review of current literature. J Clin Endocrinol Metab. 2014;99(4):1132-41. 
63. Stafford N. Vitamin D supplements poison dozens of Danish children. BMJ. 2016;354:i4534.

64. Verkaik-Kloosterman J, Beukers MH, Jansen-van der Vliet M, Ocké MC. Vitamin D intake of Dutch infants from the combination of (fortified) foods, infant formula, and dietary supplements. Eur J Nutr. Springer Berlin Heidelberg; 2015.

65. Cribb VL, Northstone K, Hopkins D, Emmett PM. Sources of vitamin D and calcium in the diets of preschool children in the UK and the theoretical effect of food fortification. J Hum Nutr Diet. 2015;28(6):583-92.

66. Ladhani S, Srinivasan L, Buchanan C, Allgrove J. Presentation of vitamin D deficiency. Arch Dis Child. 2004;89(8):781-4.

67. Beck-Nielsen SS, Brock-Jacobsen B, Gram J, Brixen K, Jensen TK. Incidence and prevalence of nutritional and hereditary rickets in southern Denmark. Eur J Endocrinol. 2009;160(3):491-7.

68. Högler W, Munns CF. Rickets and osteomalacia: a call for action to protect immigrants and ethnic risk groups. Lancet Glob Health. 2016;4(4):e229-30. Paper calls upon policy makers to urgently act on prevention of $\mathrm{NR}$ in at risk immigrant population in the wake of the global refugee crisis

69. Ward LM, Gaboury I, Ladhani M, Zlotkin S. Vitamin D-deficiency rickets among children in Canada. CMAJ. 2007;177(2):161-6.

70. Wheeler BJ, Dickson NP, Houghton LA, Ward LM, Taylor BJ. Incidence and characteristics of vitamin D deficiency rickets in New Zealand children: a New Zealand Paediatric surveillance unit study. Aust N Z J Public Health. 2015;39(4):380-3.

71. Drury R, Rehm A, Johal S, Nadler R. Vitamin D supplementation: we must not fail our children! Medicine (Baltimore). 2015;94(18): e817.

72. Gallo S, Comeau K, Vanstone C, Agellon S, Sharma A, Jones G, et al. Effect of different dosages of oral vitamin D supplementation on vitamin D status in healthy, breastfed infants: a randomized trial. JAMA. 2013;309(17):1785-92.

73. Hatun S,, Ozkan B, Bereket A. Vitamin D deficiency and prevention: Turkish experience. Acta Paediatr Int J Paediatr. 2011;100(9): 1195-9.

74. Jessiman T, Cameron A, Wiggins M, Lucas PJ. A qualitative study of uptake of free vitamins in England. Arch Dis Child. 2013;98(8): 587-91.

75. Millette M, Sharma A, Weiler H, Sheehy O, Bérard A, Rodd C. Programme to provide Quebec infants with free vitamin D supplements failed to encourage participation or adherence. Acta Paediatr Int J Paediatr. 2014;103(10):e444-9.

76. Seymen Karabulut G, Hatun S, Bideci AHE. Attitudes of pediatricians regarding prevention and treatment of vitamin D deficiency. J Clin Res Pediatr Endocrinol. 2016;8(3):368-71.

77. Moy RJ, McGee E, Debelle GD, Mather I, Shaw NJ. Successful public health action to reduce the incidence of symptomatic vitamin D deficiency. Arch Dis Child. 2012;97(11):952-4.

78. Dunnigan MG, Glekin BM, Henderson JB, McIntosh WB, Sumner D, Sutherland GR. Prevention of rickets in Asian children: assessment of the Glasgow campaign. Br Med J (Clin Res Ed). 1985;291(6490):239-42.

79. Shakiba M, Sadr S, Nefei Z, Mozaffari-Khosravi H, Lotfi MH, Bemanian MH. Combination of bolus dose vitamin D with routine vaccination in infants: a randomised trial. Singap Med J. 2010;51(5):440-5.

80. Das JK, Salam RA, Kumar R, Bhutta ZA. Micronutrient fortification of food and its impact on woman and child health: a systematic review. Syst Rev. 2013;2:67.
81. Spiro A, Buttriss JL. Vitamin D: an overview of vitamin D status and intake in Europe. Nutr Bull. 2014;39(4):322-50.

82. Calvo MS, Whiting SJ. Survey of current vitamin D food fortification practices in the United States and Canada. J Steroid Biochem Mol Biol. 2013;136:211-3.

83. Cashman KD, Kiely M. Tackling inadequate vitamin D intakes within the population: fortification of dairy products with vitamin D may not be enough. Endocrine. 2016;51(1):38-46.

84. Tulchinsky TH. The key role of government in addressing the pandemic of micronutrient deficiency conditions in Southeast Asia. Nutrients. 2015;7(4):2518-23.

85. Högler W, Aguiar M, Kiely M, Tulchinsky T. Consensus recommendations for prevention of nutritional rickets: food fortification and micronutrient supplements for global health. AIMS Public Health. 2016;3(1):40-8.

86. Thacher TD, Bommersbach TJ, Pettifor JM, Isichei CO, Fischer PR. Comparison of limestone and ground fish for treatment of nutritional rickets in children in Nigeria. J Pediatr. 2015;167(1): 148-54.e1.

87. Dabas AG, Khadgawat R. Developing indigenous therapeutic calcium supplementation for treating nutritional rickets. J Pediatr. 2015;167(1):12-4.

88. Wahl DA, Cooper C, Ebeling PR, Eggersdorfer M, Hilger J, Hoffmann K, et al. A global representation of vitamin D status in healthy populations. Arch Osteoporos. 2012;7(1-2):155-72.

89. Pettifor JM. Screening for nutritional rickets in a community. J Steroid Biochem Mol Biol. 2016;164:139-44.

90. Ayoub DM, Hyman C, Cohen M, Miller M. A critical review of the classic metaphyseal lesion: traumatic or metabolic? Am J Roentgenol. 2014;202(1):185-96.

91. Brown SD, Serveas S, Hayes LL. SPR Child Abuse Committee response regarding classic metaphyseal lesions. Am J Roentgenol. 2014;203(2):Web exclusiveaccessed via http://www.ajronline.or.

92. Ayoub DM. Limitations of radiology in rickets. Pediatr Dev Pathol. 2013;16(5):397.

93. Karpiński M, Galicka A, Milewski R, Popko J, Badmaev V, Stohs $\mathrm{S}$. Association between vitamin $\mathrm{D}$ receptor polymorphism and serum vitamin D levels in children with low-energy fractures. J Am Coll Nutr. 2017;36(1):64-71.

94. El-Sakka A, Penon C, Hegazy A, Elbatrawy S, Gobashy A, Moreira A. Evaluating bone health in Egyptian children with forearm fractures: a case control study. Int J f Pediatr. 2016;7297092

95. Al-Daghri N, Aljohani N, Rahman S, Sabico S, Al-Attas O, Alokail M, et al. Serum 25-hydroxyvitamin D status among Saudi children with and without a history of fracture. J Endocrinol Investig. 2016;39(10):1125-30.

96. Ahn J, Yu K, Stolzenberg-Solomon R, Claire Simon K, McCullough ML, Gallicchio L, et al. Genome-wide association study of circulating vitamin D levels. Hum Mol Genet. 2010;19(13):2739-45.

97. Carpenter TO, Zhang JH, Parra E, Ellis BK, Simpson C, Lee WM, et al. Vitamin D binding protein is a key determinant of 25hydroxyvitamin D levels in infants and toddlers. J Bone Miner Res. 2013;28(1):213-21.

98. Herrmann M, Farrell C-JL, Pusceddu I, Fabregat-Cabello N, Cavalier E. Assessment of vitamin D status - a changing landscape. Clin Chem Lab Med. 2016;55(1):3-16. 